\title{
$\angle$ Research Square \\ Utilization of mechanical ventilators in low resource Faculty: a cross sectional study
}

Tigist Bacha ( $\sim$ tigistbacha@yahoo.com )

Addis Ababa University

Netsanet Tsegaye

University of Gondar

\section{Wagari Tuli}

Addis Ababa University

\section{Research}

Keywords: Mechanical ventilation, Mortality, Pediatric, intensive care

Posted Date: December 11th, 2020

DOI: https://doi.org/10.21203/rs.3.rs-125439/v1

License: (a) (i) This work is licensed under a Creative Commons Attribution 4.0 International License. Read Full License 


\section{Abstract \\ Background}

Few studies are available from Africa on the use of mechanical ventilation (MV) in the pediatric intensive care unit (PICU). Knowledge of the outcome of patients on MV is critical for better use of resources and clinical decision making. We aimed to see the outcome and pattern of patients treated in a pediatric intensive care unit in a teresery hospital, which is the first study to evaluate an Ethiopian PICU.

\section{Methods}

A cross-sectional study with retrospective data collection was employed. Data were abstracted from the patients' medical records by trained health professionals. SPSS version 21 software was used for data entry and analysis. The reports were depicted descriptively using measures of central tendency, dispersion, and displayed through tables and graphs.

\section{Results}

There were 536 patients admitted during the study period. 202 (41.2\%) incidence of mechanical ventilation (MV) rate $63.6 \%$ of the participants were males and $130(59.1 \%)$ died. The most common indication for the initiation of MV was respiratory problems 46 (20.9\%). we identified 30.59/1000 ventilator days developed complications.Ventilator-associated pneumonia accounted for $18.6 \%$ of the complications with 20.9/1000 ventilator days. Survival of medical cases was better than the surgical cases (including trauma); $[\mathrm{AOR}=0.13,95 \% \mathrm{Cl}(0.04-0.413)]$ and those who have $\mathrm{MV}$ for more than 3 days are $79 \%$ more likely to die than those of less than 3 days ventilated; $(p=0.003)$. Those who have multiorgan dysfunction syndrome die more likely than the other group of patients; $[\mathrm{AOR}=0.181,95 \% \mathrm{Cl}(0.08$, $0.412)$ and the patient who had high PIM II severity score had higher mortality rate; $[A O R=35,95 \% \mathrm{Cl}(1.7$, 11)].

\section{Conclusions}

In the current study, the mortality rate of mechanically ventilated pediatric patients was high. Severity score, multi-organ dysfunction syndrome, length of stay, and being a surgical patient increased the risk of mortality. Adequate education of PICU staff on the use of mechanical ventilator and prevention of complications as well as the use of severity score is necessary.

\section{Background}

Mechanical Ventilation (MV) is a life-supporting strategy used at the time of either impending or acute respiratory failure with the aims of improving gas exchange and decreasing work of breathing $(1,2)$. 
Given the high load of respiratory problems being the primary reason for admission to the intensive care unit in low resource countries (LRIC), there is a need for proper use of MV (3-8).

There is a disparity of available resources like mechanical ventilators and trained health providers between the LRIC and high resource income countries (HRIC). Most ICUs have no adequate available resources in LRIC (3). The percentage of children receiving MV in PICUs ranges from 17-64\% in developed countries where PICUs are a well-established discipline of medicine (2). There is a great scarcity of data from African countries regarding the use of MV in PICUs. The incidence of utilizing MV in children in Egypt was $32.8 \%$ (9). The study in Nepal showed that out of the 16 pediatric ICUs, $32 \%$ had only one functioning mechanical ventilator and another $38 \%$ had two ventilators, the other units had $3-6$ ventilators $(10)$.

Despite its important role, $\mathrm{MV}$ is associated with poor outcomes and might lead to complications like shock, ventilator-associated pneumonia (VAP), pulmonary hemorrhage, pneumothorax, atelectasis, and also side effects of medications (e.g. sedatives and analgesia) $(2,11)$. Many studies in developing countries have revealed that the mortality rate ranges from $40-60 \%$ in mechanically ventilated children. A study in the PICU of Aga Khan University Hospital in Pakistan found that the mortality rate among mechanically ventilated patients was $30.5 \%$ and the complication rate was $9.4 \%$ (1). A report from Nepal revealed a $34.1 \%$ mortality rat6e (10).

The scarce resources in Ethiopia made physicians choose very difficult rationing bedside decisions because of a lack of resources like intensive care beds and mechanical ventilators (12). The information on patient characteristics and outcomes in patients requiring $\mathrm{MV}$ is critical for better use of resources and clinical decisions for the limited pediatric intensive care unit $(P I C U)(13,14)$. However, this information is not dealt with in our setting. Therefore, the present study aimed to assess the characteristics and outcomes of mechanically ventilated pediatric patients in Tikur Anbessa specialized referral hospital, Addis Ababa, Ethiopia.

\section{Methods}

\section{Setting and Study Period}

The study was conducted from September 2016 to February 2018 at Tikur Anbessa Specialized Hospital which is the largest referral and teaching hospital in Addis Ababa, the capital city of Ethiopia. The hospital used to manage children either in adult medical or surgical ICU. Starting from 2012 the first two pediatric emergency and critical care physicians for a country established a separate four-bed ICU in 2012 which is the first PICU in Ethiopia. These two physicians cover both emergency and intensive care units during the day and on-call during the night while the nights are covered by pediatric residents. Nurse to patients ratio is $1: 2$. There is no respiratory therapist.

Each PICU bed has mechanical ventilation and equipped with a monitor along with end-tidal CO2 monitoring. This unit shares a portable X-ray machine with the adult ICU which is in the next door. We use Philip V200 mechanical ventilator for respiratory support in our PICU. Mechanical ventilation in all 
patients was initiated through an Endotracheal tube. The modes of MV mostly used were synchronized intermittent mandatory ventilation (SIMV) either volume (SIMV or pressure limited, or SIMV with pressure support (PS), assist control pressure-controlled ventilation AC/PCV assist control volume-controlled ventilation AC/VCV. The other parameters set depending on the patient's condition as FIO2, PEEP, PIP, and VT. Monitoring the subjects on MV was done with clinical examination but arterial blood gas not available $\mathrm{PaO} 2$ is estimated from the saturation of oxygen and $\mathrm{PaCO} 2$ with Entidal carbon dioxide monitor, and oxygen saturation was continuously recorded through a pulse oximeter. A chest $\mathrm{X}$-ray was ordered on demand. Chest physiotherapy is done by a nurse and rarely with a physiotherapist. Subject weaning was initiated after improving clinical condition, criteria of extubation were, when the need of $\mathrm{FIO} 2<0.4$ and depend on the clinical examination.

All children during mechanical ventilation were getting intermittent doses of diazepam and morphine (which mostly available in PO form ) as sedation and analgesia mostly. Thiopental and propofol are used rarely for status epilepticus cases and very rarely midazolam and fentanyl are rarely used as it is not available. Sometimes ketamine and Sedation of perfusion rarely continuous infusion is used because of the lack of infuser pumps. The neuromuscular blocking agent was never used.

\section{Participants and Sampling Technique}

All pediatric patients who were mechanically ventilated in the pediatric ICU of TASH for at least 24 hours during the study period were included whereas those patients with incomplete charts and lost charts were excluded from the study.

\section{Study Design}

Institutional based cross-sectional study design was employed by using a review of the patient's medical charts.

\section{Data Collection Tools and Procedures}

The instrument used to collect the data for this study was a structured data abstraction tool developed from the literature review. The tool has three parts: Socio-demographic characteristics of the participants, characteristics of mechanically ventilated patients, and patient outcome.

\section{Data Analysis}

Data were checked for completeness and coded manually and entered into SPSS version 21 for analysis. Both descriptive and analytical statistical procedures were utilized. Descriptive statistics like percentage, mean, median, standard deviation, and interquartile range (IQR) were used for the presentation of characteristics of mechanically ventilated patients; and tables and graphs were also used for data presentation. Binary and multivariable logistic regression models were used with $95 \% \mathrm{Cl}$ and $p$-value less than 0.05 taken as significant. 


\section{Operational Definition}

Ventilator-associated pneumonia was diagnosed in patients on MV for more than 48 hours with a new persistent infiltrate on chest radiograph and at least 3 of the following; fever, leucopenia or leukocytosis, increased sputum production, rales, cough or worsening gas exchange (8).

\section{Ethical Consideration}

The ethical clearance was obtained from Addis Ababa University, College of Health Sciences, Departments of Emergency Medicine and Pediatrics, and Child Health Research and publication Committee.

Additionally, the confidentiality of all the data was seriously respected by not mentioning patients' identifiers in the questioner and unauthorized individuals were not allowed to access the data which was collected by using a password-protected computer.

\section{Results}

There were 537 patients admitted to the PICU in two and a half years and 220 patients met the inclusion criteria. Most of the study subjects (39.1\%) were younger than 1 year and $63.6 \%$ of the participants were males (Table 1)

Table 1: Clinical characteristics of the study population.

\begin{tabular}{|c|c|c|c|}
\hline Variable & & Frequency & Percent (\%) \\
\hline \multirow[t]{3}{*}{ Age } & $<1$ & 86 & 39.1 \\
\hline & $1-5$ & 74 & 33.6 \\
\hline & $6-12$ & 60 & 27.3 \\
\hline \multirow[t]{2}{*}{ Sex } & Male & 140 & 63.6 \\
\hline & Female & 80 & 36.4 \\
\hline Length of stay in days $(\mathrm{SD}=13.33$, mean $=9.33)$ & $1-3$ days & 93 & $42.3 \%$ \\
\hline \multirow[t]{3}{*}{ PIM 2 Score } & 4-7days & 63 & $28.6 \%$ \\
\hline & $>8$ days & 64 & $29.1 \%$ \\
\hline & Range (1-91) & $S D=23.9$ & Mean $=20$ \\
\hline
\end{tabular}

\section{Clinical presentation}


The source for admission to PICU was from the pediatric emergency department (102; 46.4\%), from the operation room $(57 ; 25.9 \%)$, from inpatient units $(47 ; 21.4 \%)$, and from another hospital $(14 ; 6.4 \%)$.

Regarding the general indication of PICU admission, 160 (72.7\%) were medical patients and 60 (23.7\%) were surgical patients. From $149(67.7 \%)$ of the children who were screened for HIV and 4 (1.8\%) were positive. The most common indication for the initiation of mechanical ventilation was respiratory problems $46(20.9 \%)$ and the mean weight in kilogram was $12.73 \pm 9.12$ (mean $\pm S D$ ) and Glasgow Coma Scale (GCS) of patients at admission was $<8$ in $73(33.2 \%)$.

\section{Table 2: Etiology of admission of the study population.}




\begin{tabular}{|c|c|c|c|}
\hline Variable (n, \%) & & Frequency & Percent \\
\hline \multirow{8}{*}{ Neurology $(41,18.7)$} & Status epilepticus & 12 & 5 \\
\hline & Brain abscess & 6 & 2.7 \\
\hline & Traumatic brain injury & 6 & 2.7 \\
\hline & Meningitis & 7 & 3.2 \\
\hline & Stroke & 4 & 1.8 \\
\hline & Brain tumor & 3 & 1.4 \\
\hline & Intra cranial hemorrhage & 2 & 0.9 \\
\hline & Spinal cord injury & 1 & 0.5 \\
\hline \multirow{12}{*}{ Respiratory $(46,20.9)$} & Pneumonia & 15 & 6.8 \\
\hline & Tuberculosis & 8 & 3.6 \\
\hline & FBA & 6 & 2.7 \\
\hline & Apnea & 4 & 1.8 \\
\hline & Aspiration pneumonia & 4 & 1.8 \\
\hline & Lung contusion & 2 & 0.9 \\
\hline & PCP & 2 & 0.9 \\
\hline & HAAD & 1 & 0.5 \\
\hline & HAP & 1 & 0.5 \\
\hline & PTE & 1 & 0.5 \\
\hline & Pulmonary edema & 1 & 0.5 \\
\hline & Severe croup & 1 & 0.5 \\
\hline \multirow{4}{*}{ Cardiac $(29,13.2 \%)$} & Post cardiac arrest & 14 & 6.4 \\
\hline & Congenital heart disease & 10 & 4.6 \\
\hline & Congestive heart failure & 3 & 1.4 \\
\hline & SVT & 2 & 0.9 \\
\hline Sepsis $(34,15.5 \%)$ & & 34 & 15.5 \\
\hline \multirow[t]{2}{*}{ Renal $(10,4.5 \%)$} & Acute renal failure & 6 & 2.7 \\
\hline & Chronic renal failure & 4 & 1.8 \\
\hline \multirow[t]{2}{*}{ Neuromascular $(19,8.6 \%)$} & Gulian Barrie syndrome & 19 & 8.6 \\
\hline & Superior mediastinal mass & 5 & 2.3 \\
\hline
\end{tabular}




\begin{tabular}{|c|c|c|c|}
\hline \multirow{2}{*}{ Malignancy $(8,3.6 \%)$} & Anterior mediastinal mass & 2 & 0.9 \\
\hline & Tumor lysis syndrome & 1 & 0.5 \\
\hline \multirow[t]{4}{*}{ Other $(33,15 \%)$} & Post- operation & 28 & 12.7 \\
\hline & Poisoning & 2 & 0.9 \\
\hline & Diabetic ketoacidosis & 1 & 0.5 \\
\hline & Uremic encephalopathy & 2 & 0.9 \\
\hline
\end{tabular}

FBA: foreign body aspiration PTE: Pulmonary thromboembolism, HAP: Hospital-acquired pneumonia, HAAD: Hyperactive airway disease, PCP: Puemocystic carni pneumonia. SVT: Supraventricular tachycardia

\section{Mode of ventilation and Weaning Method}

The access to airways was through endotracheal tubes in most cases, while 6 cases were tracheostomized (2.7\%). Regarding the modes used at the initiation of mechanical ventilation, SIMV + PS , SIMV/VSV , AC/PCV , AC/VCV, and BIPAP/CPAP were used in $80 \%, 8.6 \%, 4.5 \%, 3.2 \%, 3.6 \%$ of cases respectively. The duration of MV ranged from (1-90) days with a median of 4.4 with IQR (2-10.3). The weaning methods recorded for this patients were CPAP alone 54(24.5\%), direct oxygen trial $14(6.4 \%)$, PS with CPAP 12(5.5\%), and unplanned accidental extubation 3(1.4\%).

\section{Complications}

Complication occurred in $60(27.3 \%)$ patients that is 30.55 per 1000 ventilation days, categorized as VAP 41(18.6\%) (20.9/ 1000 ventilation days ), Pneumothorax 15 (6.8\%) (7.6/1000 ventilation), atelectasis $11(5 \%)(5.6 / 1000$ ventilation) and post-extubation stridor $1(0.5 \%)$ ( 0.5 ventilation). More than one complication occurred in 8 (3.6\%) patients. About half (57.3\%) of the patients developed multiple organ dysfunction Syndrome (MODS).

\section{Outcome of patients}

Among the total study participants, 130(59.1\%) died where sepsis was the leading cause of death 59 (26.8\%). From the survivors, $75(34.1 \%)$ transferred to the ward, $12(5.5 \%)$ left the hospital against medical advice and $3(1.4 \%)$ were discharged (Table 3 ).

Table 3: Outcome of mechanically ventilated pediatric patients in TASH PICU, $(n=220) 2018$. 


\begin{tabular}{|llll|}
\hline Variable & & Frequency & Percent \\
\hline Outcome & Survived & 90 & 39.9 \\
\hline \multirow{2}{*}{ Cause of death } & Not survived & 130 & 59.1 \\
\cline { 2 - 4 } & Sepsis & 59 & 26.8 \\
\cline { 2 - 4 } & ARDS & 30 & 13.6 \\
\cline { 2 - 4 } & Brain death & 17 & 7.7 \\
\cline { 2 - 4 } & Intractable heart failure & 12 & 5.5 \\
\cline { 2 - 4 } & Other* & 13 & 5.9 \\
\cline { 2 - 4 } & &
\end{tabular}

**Renal failure, Surgical site bleeding, Tension pneumothorax, Blocked ETT, Intracranial hemorrhage.

\section{Logistic Regression Results}

Medical cases survived better than the surgical cases (including trauma); [AOR= $0.13,95 \% \mathrm{Cl}(0.04-0.413)$ ] and those who have mechanical ventilation for more than 3 days were $79 \%$ more likely to die than those with less than 3 days of ventilation; $(p=0.003)$. The patients without MODS were more likely to survive than those with MODS [AOR $0.181,95 \% \mathrm{Cl}(0.08,0.412)]$. The patients who had a high PIM II score had a higher death rate $[\mathrm{AOR}=4.35,95 \% \mathrm{Cl}(1.7,11)]$ (Table 4).

Table 4: Logistic regression analysis of associated factors with mortality in mechanically ventilated pediatric patients in TASH pediatrics ICU $(n=220) 2018$. 
Final Outcome

$\operatorname{COR}(95 \% \mathrm{Cl})$

AOR(95\% Cl)

Variable

\section{Survivor Non}

(n) survivor

(n)

\begin{tabular}{|c|c|c|c|c|c|}
\hline \multirow[t]{3}{*}{ Age } & $<1$ year & 31 & 55 & \multicolumn{2}{|l|}{$1.27(0.64,2.49)$} \\
\hline & 1-5 year & 34 & 40 & $0.84(0.42,1.67)$ & \\
\hline & 6-12 year & 25 & 35 & 1 & \\
\hline \multirow[b]{2}{*}{ Sex } & Female & 32 & 48 & $0.94(0.54,1.64)$ & \\
\hline & Male & 58 & 82 & 1 & \\
\hline \multirow[b]{2}{*}{ Type of cases } & Medical & 48 & 112 & $5.44(2.933,10.730)^{\star}$ & 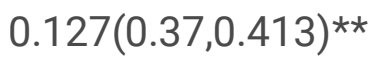 \\
\hline & Surgical & 42 & 18 & 1 & \\
\hline \multirow{8}{*}{$\begin{array}{l}\text { Admission } \\
\text { diagnosis }\end{array}$} & Neurology & 18 & 23 & $0.61(0.248,1.49)$ & \\
\hline & Respiratory & 18 & 28 & $0.61(0.26 .1 .41)$ & \\
\hline & Cardiac & 11 & 18 & $0.45(0.18,1.14)$ & \\
\hline & Sepsis & 6 & 28 & $0.20(0.07,0.58)^{\star}$ & \\
\hline & Neuromuscular & 15 & 4 & $3.42(0.97,11.96)^{\star}$ & \\
\hline & Malignancy & 2 & 6 & $0.30(0.055,1.67)$ & \\
\hline & Renal & 2 & 10 & $0.20(0.07,0.58)^{\star}$ & \\
\hline & Other & 23 & 10 & 1 & \\
\hline \multirow{4}{*}{$\begin{array}{l}\text { Indication for } \\
\mathrm{MV}\end{array}$} & $\begin{array}{l}\text { Respiratory } \\
\text { failure }\end{array}$ & 3 & 15 & $25(2.10,29.28)^{\star}$ & \\
\hline & Cardiovascular & 27 & 34 & $6.29(0.69,7.14)^{\star}$ & $7.149(1.30,39.48)$ \\
\hline & Neurology & 55 & 80 & $7.27(0.83,63.97)$ & \\
\hline & Other(post op) & 5 & 1 & 1 & \\
\hline \multirow{3}{*}{$\begin{array}{l}\text { Length of } \\
\text { stay on MV }\end{array}$} & 1-3 days & 26 & 67 & $0.2(0.11,0.43)$ & $0.19(0.068,0.57)^{\star \star}$ \\
\hline & $4-7$ & 23 & 40 & $0.32(0.156,0.67)$ & $0.26(0.09,0.77)^{\star \star}$ \\
\hline & $>8$ & 41 & 23 & 1 & \\
\hline \multirow[t]{2}{*}{ Comorbidities } & SAM & 6 & 6 & $1.0(0.167,5.98)$ & \\
\hline & Malignancy & 14 & 23 & $0.609(0.131,2.83)$ & \\
\hline
\end{tabular}




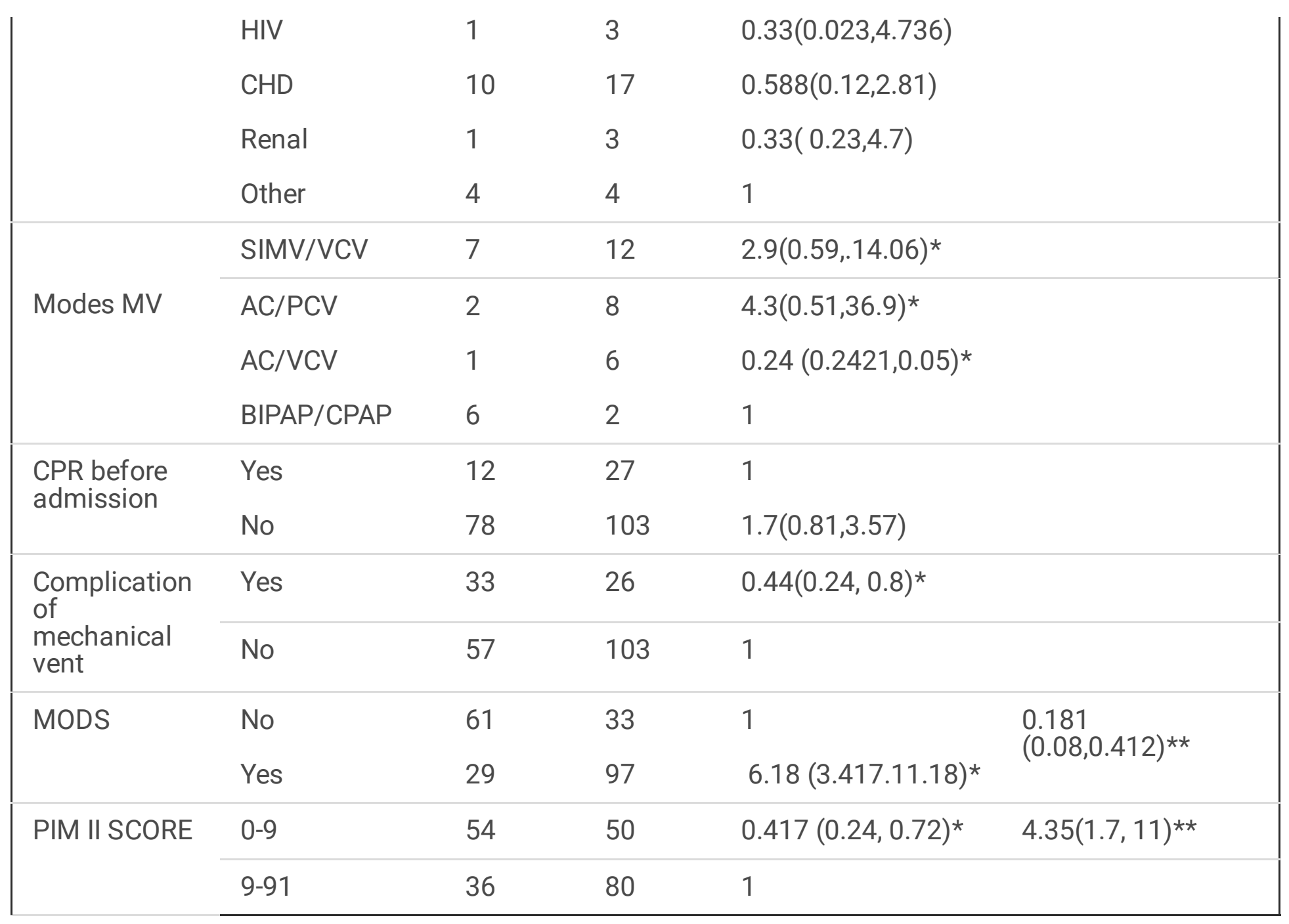

Mean and SD) (20,23.9), MIN/MAX (1-91)

${ }^{*} P$ value $<0.2$ for $C O R$, ** $P$ value $<0.05$ for $A O R$

\section{Discussion}

The COVID pandemic exposed the burden and need for a mechanical ventilator globally. This scarcity is much exaggerated in Africa where fewer than 2,000 working ventilators in public hospitals available across 41 African countries, compared with more than 170,000 in the U.S. Ten countries in Africa have no ventilator at all(14). There is scarce available data from African countries regarding the use of MV in the intensive care unit in particularly in pediatrics. Even if most data's from resource-limited setting are underreported; there are a high burden and mortality of respiratory failure in LRIC compared to HRIC, the provision of mechanical ventilators help save lives if implemented in a thoughtful fashion (14). This is the first study in Ethiopia to look for characteristics and short-term outcomes of mechanically ventilated children as it is important to know how this scare resource being used.

There were 536 Patients admitted during the study period with 202 (41.2\%) supported by mechanical ventilation. In a previous study in Gondar university ie the Northern part of Ethiopia $10 \%$ of pediatric ICU 
admissions required $\mathrm{Mv}(15)$ on the other hand children admitted to the general ICU of the university hospital southeastern part of Ethiopia (Jimma) it was 37\% (16). Both these are lower than the current study. This could be Tikur Anbessa is last referral hospital in Ethiopia where more complicated cases and also e Gondar hospital used 1 ventilator and Jimma used shared the general ICU that might have a role also. Other studies reported a varying incidence of MV use in PICU: $30 \%$ in 16 United States PICUs (17); in Egypt of 32.8\% (9), 34.6\% in an Italian study (18), 50.7\% in Pakistan (1) and 52\% in Sri Lanka (19).

This study identified that respiratory (20.9\%) was the most common indication for admission. A Prospective cohort Brazil and retrospective follow up study in Turkey and another multicenter study showed acute respiratory failure was a primary reason for MV $59.18 \%$, and $72 \%, 64.8 \%$ respectively $(4,20$, 21). However, our finding differs from a study done in a prospective observational study in Cairo in which the main indication for $\mathrm{MV}$ was neurologic cases 38.9\% (9) and the discrepancy might be due to respiratory diseases like pneumonia that are common in Ethiopia and is one of the top causes of mortality in the country for children younger than 5 years of age (22).

This study found that SIMV was the most commonly used MVmode (80.0\%). Similarly, the retrospective review in Pakistan (1) and prospective descriptive study in India (2), Egypt (9), Turkey (21), and Bangladesh(23) reported the commonest ventilator mode to be SIMV (21). Several published reports also found that SIMV the most commonly used mode of MV in multiple PICUs in the USA (17). The weaning method employed was CPAP alone $24.5 \%$ whereas the study of the group from Cairo showed that pressure support (PS) with CPAP was the preferred method of weaning in $74.7 \%$ of the cases (9). The difference could be due to the preference of the physicians and patients' capacity of maintaining their saturation on both methods.

The length of MV support in this finding showed a median of 4.4 days [IQR 2-10.3] and a mean of 9.3 ( \pm 13.33). The duration of MV ranged from 4-9 days in other reports. The median duration of MV was 3.1, 4.5, 5, 9 days in London Ontario (24), in Italian (18), Latin America (6), and in Cairo (9) respectively. This variation could be due to the variation in the reason for admission.

In the present study, we identified 60 (27.3\%) and 30.59/1000 ventilator days developed complications. Though it is lower than the reported in Cairo (39.9\%) and also 40\% in Principi et al (24). This study showed VAP of $18.6 \%$ with 20.9 / 1000 ventilator days which is similar to Meligy et al where VAP had accounted for 20.19 per 1000 ventilation days(9). Higher values VAP also reported in (36.2\%) India (2) and Egypt (31.8/1000) ventilator-days (24). The atelectasis occurred in $5 \%$ in this study which is similar to $(4.6 \%)$ in Pakistan (1) and (4.4\%) in Egypt (9).

Logistic regression analysis reflected, predictors of mortalities were the presence of MODS; higher severity score, surgical rather than medical cases (including trauma), and pronged duration of MV. Our MODS rate of $57.3 \%$ of the cases higher than studies done in (7.6\%) India (2) and (41.3\%) Egypt (9). The higher discrepancy in our study might be due to delayed admission to PICU, a limited early resuscitation practice in our setting which is a crucial method of preserving organs from failing. Prolonged MV more than 3 days were $79 \%$ more likely to die than those of less than 3 days ventilated; $(p=0.003)$. This is similar to 
the Pakistan study where prolonged mechanical ventilation (>10days) is an important predictor of mortality (1). Similarly, those who are on MV died more in Italian study than those who are not MV (18).

Higher Severity score showed higher mortality in our study and which is similar to multiple other studies. Surgical cases die more than the medical case because we included those severs traumatic injuries in this list. This study revealed that the mortality rate was $59.1 \%$ which is higher than in Czech Republic $3.5 \%$ (27), in Italy 6.7\% (18), in sir Lanka 27.6\% (19), in Pakistan 30.3\%(1), India 43.8\%(2) and in Egypt study (9) respectively. Also it is higher than from Faris et al from international study of 36 Picus of seven countries $15.6 \%(28)$, The report in developed countries ranged from $1.6-15 \%(4-7,17,18,27)$. Sepsis (26.8\%) and ARDS (13.6\%) were among the common causes of mortality in our study Dahlem et al also showed the same (29).

This higher rate of mortality with sever PIM score and MORD speak about late admission of PICU patients because of the limited PICU bed and ventilators, delayed recognition and resuscitation of critically ill children, lack of PICU trained enough staff who covers undividedly ICU both during and night. As the previous study showed the standardized mortality ratio (SMR) improved significantly with intensivist care compared to non-specialist care (30) therefore there is a huge need for training of the pediatric intensivists. The limited knowledge of health providers on the use and management of mechanical ventilator; unavailability of basic tests for mechanical ventilators like blood gas and lack of syringe pumps to administer sedation and other necessary drugs all these needs to improve the outcome of ventilated children.

\section{Limitations Of The Study}

Secondary data were used for this study; so that it was difficult in getting all the necessary data which are important for the study like anthropometry measurements. None of the patients had a blood gas analysis.

\section{Conclusion}

This study identified that the mortality rate of mechanically ventilated pediatric patients in Tikur Anbesa specialized hospitals. The main reason for the initiation of MV at PICU was respiratory failure and predictor of mortality are higher PIM II score, pronged duration of MV, the presence of MODS; the surgical case with nonmedical score were significant predictors of PICU mortality.

\section{Abbreviations}

ARDS: Acute respiratory distress syndrome, CPAP:Continuous positive airway pressure, ETT:Endotracheal tube, FIO2:Fraction of inspired oxygen, ICU:Intensive care unit, IVH:Intraventricular hemorrhage, MODS:Multiple organ dysfunction syndromes, MV:Mechanical ventilation, PEEP:Peak end-expiratory pressure, PICU:Pediatric intensive care unit, PS:Pressure support, SIMV:Synchronized intermittent mandatory ventilation, SPSS:Statistical package for social sciences, US:United States, VAP:Ventilatorassociated pneumonia 


\section{Declarations}

\section{Ethics approval and consent to participate}

The ethical clearance was obtained from Addis Ababa University, College of Health Sciences, Departments of Emergency Medicine, and Department of Pediatrics and child health research and publication committee.

\section{Consent for publication}

Notapplicable

\section{Availability of data and materials}

The datasets used and/ or analyzed during the current study are available from the corresponding author on resoanable request.

\section{Competing Interest}

We have no competing interest.

\section{Funding statement}

This work was funded by Addis Ababa University College of Health Science.

\section{Authors' contribution}

TH: selected topic, help writing of the proposal, analyzed the data and wrote the manuscript, NT: wrote a draft of the proposal, collected data, and review the manuscript, WT: assisted in the design of critical review of the proposal and edited the final manuscript .All authors read and approved the final draft of the manuscript for publication.

\section{Acknowledgment}

We would like to thank Tikur Anbessa hospital staff of the chart record office, the pediatric intensive care department staff for their collaboration. Dr Uri Pollak head of Pediatric Critical Care at Hadassah University Medical Center, Jerusalem, Israel for giving us commont on the manuscript .

\section{Author details}

1Department of Pediatric and Child health, Addis Ababa University College of Health Sciences, Addis Ababa, Ethiopia. 2Department of Emergency and critical care, University of Gondor, Gondor, Ethiopia. 3Department of Emergency Medicine, Addis Ababa University College of Health Sciences, Addis Ababa, Ethiopia. 


\section{References}

1. Mukhtar B, Siddiqui NR, Haque A. Clinical characteristics and immediate-outcome of children mechanically ventilated in PICU of Pakistan. Pakistan journal of medical sciences. 2014;30(5):927.2.

2. Ayesha Begum DSV, Dr.C.Suresh Kumar. A Prospective Study On Clinical Profile And Outcome Of Ventilated Children In A Pediatric Intensive Care Unit Of A Tertiary Care Teaching Hospital, Telangana: IOSR Journal of Dental and Medical Sciences (IOSR-JDMS) Apr. 2016;15(Issue 4 Ver. VIII ): 13-7.

3. Vijay Krishnamoorthy, Monica S. Vavilala, Charles N. Mock the need for ventilators in the developing world: An opportunity to improve care and save lives J Glob Health. 2014 Jun; 4(1):

010303.doi: 7189/jogh.04.010303 PMCID: PMC4073242 PMID: 24976958

4. Silva DC, Shibata AR, Farias JA, Troster EJ. How is mechanical ventilation employed in a pediatric intensive care unit in Brazil? Clinics (Sao Paulo) 2009;64(12):1161-6. doi: 10.1590/S180759322009001200005. [PMC free article] [PubMed] [CrossRef] [Google Scholar]

5. Ghaffari J, Abbaskhanian A, Nazari Z. Mortality Rate in Pediatric Intensive Care Unit (PICU): A Local Center Experience. International Journal of Pediatrics. 2014;2(3.2):81-8.

6. Julio A. Farias AF, Ezequiel M; Juan C. Flores, Arístides B, Amanda M, Rossana P, Flavia P, María J, Bettina von D, Alejandro D, Ine's Z, Cesar Z, Eduardo T, Yolanda P, Carlos F, Helena A, Vidal N, Andre's E. Mechanical ventilation in pediatric intensive care units during the season for acute lower respiratory infection: . Pediatr Crit Care Med 2011; 12, (No. 5).

7. Cullen DJ, Sweitzer BJ, Bates DW, Burdick E, Edmondson A, Leape LL. Preventable adverse drug events in hospitalized patients: a comparative study of intensive care and general care units. Critical care medicine. 1997; 25(8):1289-97.

8. Giraud T, Dhainaut J-f, Vaxelaire J-f, Joseph T, Journois D, Bleichner G, et al. latrogenic complications in adult intensive care units: a prospective two-center study. Critical care medicine. 1993; 21(1):40-51.

9. Meligy BS, Kamal S, El Sherbini SA. Mechanical ventilation practice in Egyptian pediatric intensive care units. Electronic physician. 2017; 9(5):4370.

10. Aayush Khanal1, Arun Sharma, Sangita Basnet.Current State of Pediatric Intensive Care and High Dependency Care in Nepal. PediatrCrit Care Med. 2016 Nov; 17(11):1032-1040.

PMID: 27679966 DOI: 1097/PCC.0000000000000938

11. Rimensberger PC, Cheifetz IM. Ventilatory support in children with pediatric acute respiratory distress syndrome: proceedings from the Pediatric Acute Lung Injury Consensus Conference. Pediatric Critical Care Medicine. 2015;16(5_suppl):S51-S60.

12. Frehiwot Berhane Defaye1,Dawit Desalegn2, Marion Danis, Samia Hurst, Yemane Berhane, Ole Frithjof Norheim1 , Ingrid Miljeteig A survey of Ethiopian physicians' experiences of bedside rationing: extensive resource scarcity, tough decisions and adverse consequences BMC Health Services Researchvolume 15,Article number: 467 (2015)

13. Jeong B-H, Suh GY, An JY, Park MS, Lee JH, Lee M-G, et al. Clinical demographics and outcomes in mechanically ventilated patients in Korean intensive care units. Journal of Korean medical science. 
2014; 29(6):864-70.

14. Vijay Krishnamoorthy, Monica S. Vavilala, and Charles N. Mock the need for ventilators in the developing world: An opportunity to improve care and save lives J Glob Health. 2014 Jun; 4(1): 010303. doi: 10.7189/jogh.04.010303

15. .Abebe T, Girmay M, G/Michael G, Tesfye M. The epidemiological profile of pediatric patients admitted to the general intensive care unit in an Ethiopian university hospital.Int J Gen Med. 2015; 8: 63-67. doi: 10.2147/ IJGM.S76378 PMCID: PMC4319554.

16. Ashenafi Tazebew, Tigist Bacha Heye, Biniyam Chakilu Tilahun admission patten and outcome in a pediatric intensive care uni of Gonder university hospital Ethiop Med J, 2019, Vol. 57, No. 2

17. Khemani RG, Markovitz BP, Curley MA. Characteristics of children intubated and mechanically ventilated in 16 PICUs. Chest. 2009; 136(3):765-771. DOI: 10.1378/chest.09-0207. [PMC free article] [PubMed] [Google Scholar]

18. Wolfler A, Calderoni E, Ottonello G, Conti G, Baroncini S, Santuz P, et al. Daily practice of mechanical ventilation in Italian pediatric intensive care units: a prospective survey. Pediatric Critical Care Medicine. 2011;12(2):141-6.

19. Vijayakumary T dJ, Sarathchandra J, Kumarendran B. Prospective study of ventilated patients in the pediatric medical intensive care unit of Lady Ridgeway Hospital. Sri Lanka J Child Health. 2012;41(3):114-117. [Google Scholar]

20. Farias JA1, Frutos F, Esteban A, Flores JC, Retta A, Baltodano A, Alía I, Hatzis T, Olazarri F, Petros $A$, Johnson $M$. What is the daily practice of mechanical ventilation in pediatric intensive care units? A multicenter study. Intensive Care Med. 2004 May;30(5):918-25. Epub 2004 Mar 17.

21. Kendirli T, Kavaz A, Yalaki Z, OzturkHismi B, Derelli E, Ince E. Mechanical ventilation in children. Turk J Pediatr. 2006;48(4):323-7. [PubMed] [Google Scholar]

22. In Ethiopia, pneumonia is a leading single disease killing under-five children Unicef Ethiopia Novemebr 13,2014 https://unicefethiopia.org/2014/11/13/in-ethiopia-pneumonia-is-a-leading-singledisease-killing-under-five-children/ accessed may 25,2020

23. Mohammad Mashiur Rahman1, Dr. Md. Shafiul Hoque2, Dr. Asma Hoque3, Dr. Mohammed AkterHossan Masud4 Clinical characteristics and immediate-outcome of children mechanically ventilated in PICU: A study in Dhaka Shishu (Children) Hospital, Dhaka, Bangladesh International Journal of Medical and Health Research Volume 5; Issue 7; July 2019; Page No. $72-75$

24. Principi T, Fraser DD, Morrison GC, Farsi SA, Carrelas JF, Maurice EA, et al. Complications of Mechanical Ventilation in the Pediatric Population. Pediatr Pulmonol. 2011;46(5):452-7. doi: 10.1002/ppul.21389. [PubMed] [CrossRef] [Google Scholar]

25. Mohammad Hassan Aelami, MojtabaLotfi\& Walter Zingg Ventilator-associated pneumonia in neonates, infants and children Antimicrobial Resistance and Infection Control volume 3, Article number: 30 (2014)

26. Alexis M. Elward, David K. Warren and Victoria J. Fraser Ventilator-Associated Pneumonia in Pediatric Intensive Care Unit Patients: Risk Factors and OutcomesPediatrics May 2002, 109 (5) 758-764; 
DOI: https://doi.org/10.1542/peds.109.5.758

27. Fedora M, Kroupova L, Kosut P, Fanta I, Hrdlicka R, Kobr J, et al. Mechanical ventilation on paediatric intensive care units in Czech Republic. Anasthesiologie, Intensivmedizin, Notfallmedizin, Schmerztherapie: AINS. 2005;40(3):173-8.

28. Faris JA FF, Cassado J, Siaba A, Retta A, Fernandez A, BaltodanoA,Ko IJ, Johnson M, Esteban A factors associated with the prognosis of mechanically ventilated infants and children. medintensiva,. 2006 Dec;30(9)::425-31.

29. Dahlem P, van Aalderen WM, Hamaker ME, Dijkgraaf MG, Bos AP. Incidence and short-term outcome of acute lung injury in mechanically ventilated children. EurRespir J. 2003;22(6):980-5. doi: 10.1183/09031936.03.00003303. [PubMed] [CrossRef] [Google Scholar]

30. Goh AY, Abdel-Latif ME, Lum LC. Impact of 24-hour critical care physician staffing on case-mix adjusted mortality in paediatric intensive care. Lancet2001; 357:445-6. 